\section{Financial Toxicity in Patients With Cancer: What a Tangled Web We Weave}

\author{
Benyam Muluneh, PharmD, BCOP, CPP
}

I n his 1808 epic poem, Scottish author Sir Walter Scott beautifully expresses a forbidden love story. ${ }^{1}$ In it, there are layers of deception by the ill-fated lovers and an attempted cover-up that was spinning out of control. Scott wrote the infamous line, "Oh, what a tangled web we weave/When first we practice to deceive," to describe how attempting to cover up deception eventually leads to catastrophic failure-as we see by the end of this poem.

When reflecting on this poem and that line, I couldn't help but think about how accurately it describes how much our current efforts to help patients with cancer acquire their expensive chemotherapy feels a bit like a tangled web. As an oncology clinical pharmacist, in addition to providing education to my patients, assessing adherence to oral anticancer drugs, and managing side effects, I am often involved in having very sensitive conversations about financial toxicity. After patients have had a conversation with their oncologist about starting a particular type of chemotherapy, they come to me to find out whether they can afford it. The patients are apprehensive and exhausted. Having been given a cancer diagnosis, now they are thinking about how they will afford therapy.

I was prompted to write this after I finished speaking with the daughter (let's call her Beth) of a patient who was starting an oral anticancer drug (venetoclax) for acute myeloid leukemia. I explained to Beth that although she was "told" the treatment would start next week, it all depended on our ability to jump through the many financial hoops involved. She paused. In this peri-COVID world in which we need to have these conversations by phone, I couldn't see her facial expression, but I could sense her dismay. "Beth, I am sure we can get her the drug. Our team is quite good at getting these drugs paid for." That is my usual canned response. And I know we can.

Our team of technicians is excellent. We are very good and efficient at obtaining patients their lifesaving drugs. This is especially critical in the leukemia clinic, where delays in initiation can lead to adverse clinical outcomes. When I think about drug costs in the United States, especially for those on Medicare, nothing short of a radical (almost miraculous) policy change can bring about palpable differences for our patients. At this point, it is unclear whether patients with cancer will benefit from moderate policy proposals. A lot of the modeling that is used to project benefit to patients does not take into account the almost certain villainous retaliation of the insurance/pharmacy benefit manager (PBM) industry. So if the current system is bad, why aren't more of our patients out in the streets protesting for better drug access? It is because of the tangled web we weave.

What I am referring to is an unbelievably complex medication assistance program that we have designed to protect patients from corporate greed. It may differ in complexity and design based on the institution, but there is usually a team of people who are working extremely hard on medication access (Figure 1). These are the unsung heroes of our cancer care delivery team. When prescriptions get sent to our pharmacy, the first barrier to cross is prior authorization. Nearly all patients with Medicare Part D will require a prior authorization for an oral anticancer drug. After filling out several forms to justify use of the drug, the prior authorization may be approved. If not, there are 4 layers of appeals, which can

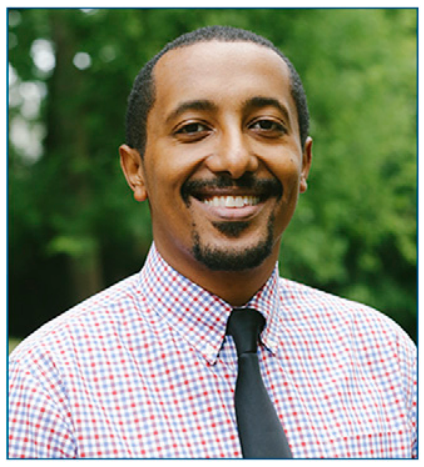

BENYAM MULUNEH, PharmD, BCOP, CPP

Benyam Muluneh, PharmD, BCOP, CPP, is an Assistant Professor at University of North Carolina Eshelman School of Pharmacy and a Clinical Pharmacist Practitioner with the Leukemia Program at University of North Carolina's Cancer Hospital.

doi: $10.6004 /$ jnccn.2020.7649

The ideas and viewpoints expressed in this commentary are those of the author and do not necessarily represent any policy, position, or program of NCCN. 


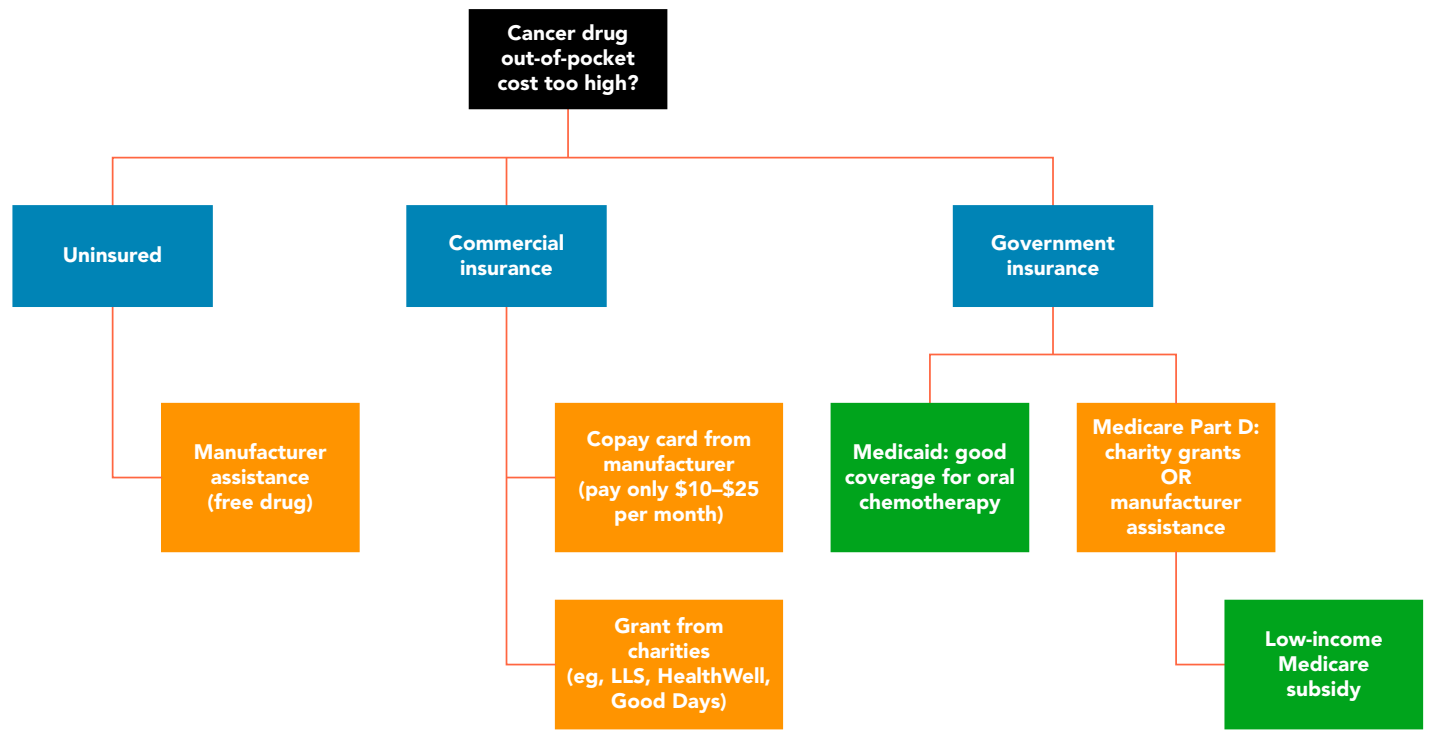

Figure 1. Complex medication assistance process. Orange entries indicate partial or full temporary support from the pharmaceutical industry; this support will cease once drugs are off patent and there are generic competitors. Green entries indicate favorable insurance coverage for low-income insured patients.

Abbreviation: LLS, Leukemia \& Lymphoma Society.

eventually land you in front of a judge as a plaintiff (which I have done 3 times). Once approved, the next hurdle is the extraordinarily high copay for oral anticancer drugs. Because most patients with cancer do not qualify for Medicare low-income subsidy, they are automatically catapulted into a "specialty tier"2_or as I call it, "predator tier," because the relationship that PBMs and insurers have with patients with cancer is that of predator and prey. In this tier, where patients have to participate in "cost sharing," they are responsible for $25 \%$ to $50 \%$ of the drug's cost, which ends up being $\$ 1,000$ to $\$ 5,000$ per month (depending on the specific plan).

I hate when patients ask me how much their chemotherapy will cost. When Beth asked me how much the venetoclax will cost, I repeated my canned response: "I am sure we can get your mom the drug. Our team is very good." And I know we can.

Patients with commercial insurance often benefit directly from copay assistance support from the manufacturers. However, because of the 1972 Federal Anti-Kickback Statute, Medicare patients cannot receive direct copay assistance support from pharmaceutical companies. ${ }^{3}$ Currently there are several third-party charitable organizations, often funded by the pharmaceutical industry, who provide copay assistance to our patients. But then I wonder: What if these organizations run out of money? That has happened numerous times for my patients with chronic myeloid leukemia. I don't share my fears with Beth. Although Beth didn't ask, some patients do ask me, "What happens if you can't get funding from the charity?" Then we beg. Pharmaceutical companies have a "free drug" program that requires an application process. Although these programs are helpful, when drugs lose their patent and are no longer profitable, free drug assistance programs go away. We have seen this happen for patients with acute promyelocytic leukemia-a very curable leukemia treated with a generic oral anticancer drug (tretinoin), but among whom poorer survival has been observed due to lack of drug access. ${ }^{4}$

With the increase in availability of many lifesaving (albeit several with underwhelming benefit) and costly oral anticancer drugs, I worry so much about my patients now, and even more so about them in the future. I know Beth's mom will start on treatment. It will take a lot of phone calls, forms, angry appeal letters, and maybe even a court hearing, but she will get her therapy. But this level of grassroots patient advocacy can only carry us so far. Eventually, the tangled web of our medication assistance practices will not be sustainable without urgent intervention from policymakers.

Interestingly, Sir Walter Scott died because he couldn't afford medical care. Like so many of our patients, he didn't want to admit that he couldn't afford to pay for care. Our patients, like Sir Walter Scott, are vulnerable, and our current systems of reassurance are simply tangled webs of deception. Extensive and disruptive changes are needed before these temporary systems finally spin out of control.

Disclosures: Dr. Muluneh has disclosed that he has not received any financial considerations from any person or organization to support the preparation, analysis, results, or discussion of this article.

Correspondence: Benyam Muluneh, PharmD, BCOP, CPP, University of North Carolina Eshelman School of Pharmacy, 301 Pharmacy Lane, CB 7569 Chapel Hill, NC 27599. Email: bmuluneh@unc.edu 


\section{References}

1. Scott W. Marmion: A Tale of Flodden Field. Edinburgh, England: J. Ballantyne and Co.; 1808.

2. What Medicare Part D drug plans cover. Accessed August 2,

2020. Available at: https://www.medicare.gov/

drug-coverage-part-d/what-medicare-part-d-drugplans-cover
3. Criminal Penalties for Acts Involving Federal Health Care Programs, 42 USC §1320a-7b (2010). Accessed August 2, 2020. Available at: https://www.law.cornell.edu/uscode/text/42/1320a-7b

4. Jamy O, Xavier AC, Costa LJ. Impact of insurance status on survival of patients diagnosed with acute promyelocytic leukemia in the United States [abstract]. Blood 2018;132(Suppl 1):Abstract 321. 